\title{
Figura bíblica de Maria e sua inculturação popular
}

\author{
Stefano De Fiores*
}

$\mathrm{O}$ argumento é importante e urgente, pois trata-se de uma realidade muito vivida na Calabria e em particular em Crotone onde a veneração da Mãe do Senhor sob o título de Madonna di Capocolonna está dentro do coração dos fiéis e é objeto de atenção pastoral por parte dos bispos e dos presbitério.

Para estabelecer a relação entre a figura bíblica de Maria e sua inculturação popular devemos previamente enfrentar dois problemas: qual é a situação atual da piedade popular e qual atitude devemos assumir em relação a ela?

Depois, deteremos nossa atenção sobre a imagem popular de Maria, após termos situado a sua figura no universo da cultura popular.

Por fim, tentaremos propor uma mariologia popular, a partir de alguns princípios e critérios.

\section{A situação atual da Piedade Popular}

Não podemos enfrentar com seriedade este argumento, sem levarmos em conta algumas interrogações já formuladas na Communio de 1987, ainda mais válidas hoje:

Qual é hoje o valor da religiosidade popular quando a sociedade está sujeita a transformações rápidas e a concepções indiferentes ou em contraste com a vida cristã?

\footnotetext{
* Traduzido pelo Prof. Dr. Abimar Oliveira de Moraes, do Departamento de Teologia da PUC-Rio.
} 
Numa sociedade secularizada, para o homem moderno, ela tem uma razão plausível de existir? Qual é o seu valor numa igreja particular a quem é solicitado um processo de conversão e um anúncio contínuo e em situação nova do evento salvífico de Jesus Cristo? ${ }^{1}$

\section{1. colapso ou vitalidade?}

Responde, em 2001, um especialista em religiosidade popular: Aldo N. Terrin, que, já em 1979, opondo-se à corrente marxista dominante, sublinhava que ela não pode ser vista de forma primária como «religião das classes subalternas», mas sim, como expressão instintiva, pré-categorial ${ }^{2}$ A tese de Terrin é que, atualmente, na Itália, a religiosidade popular parece dar «sinais de enfraquecimento», até mesmo de «colapso» ou «adormecimento profundo», sob a influência dos mass media que realizam «um nivelamento e enfraquecimento das subculturas, realizando uma obra de cancelamento do folclore e das tradições regionais». Surgem «novos filões» ou formas de «aproximação ao sagrado através de uma contigüidade de tipo afetivo e experiencial» (começando pelos grupos carismáticos até a New Age), na qual transvasa-se a religiosidade popular. Nessa ótica «a religiosidade popular não desaparece, mas muda de significado»:

A religiosidade popular permanecerá sempre como «a religiosidade do coração», «o sentimento de dependência», o lugar onde se experimenta «o sentido e o gosto pelo infinito» (Schleiermacher), a «força da vida que se dilata» (Van der Leeuw), o «bom senso» de viver, como aspiração de quem tem ainda esperança e a invocação daqueles que, não podendo alcançar a plenitude que desejam, enveredam pela estrada da invocação, da oração e da súplica ${ }^{3}$

Seguindo outros estudiosos como M. Meslin e V. Turner, o autor vincula a religiosidade popular ao Lebenswelt (mundo da vida), que se exprime em dois filões fundamentais: a) a relação imediata com o divino e com o

\footnotetext{
${ }^{1}$ B. Testa, «La religiosità popolare nel magistero di Giovanni Paolo II», in Communio n. 95(1987), 57.

${ }^{2}$ A.N. Terrin, «La religiosità popolare in prospettiva fenomenologica», in Aa.Vv., Ricerche sulla religiosità popolare, Bologna 1979, 119-148.

${ }^{3}$ A.N. Terrin, «Religiosità popolare e liturgia: I. Dal punto di vista delle scienze umane», in D. Sartore - A.M. Triacca - C. Cibien (ed.), Liturgia, Dizionari San Paolo, Cinisello Balsamo 2001, 1598.
} 
sagrado, que se concretiza numa forte «iconofilia» ou amor pelas imagens e pelos sinais do sagrado; b) o aspecto utilitário que une salvação e saúde, contra a visão desencarnada e angelical da fé, e que se manifesta no $d o u t$ des da peregrinação e da oração.

Parece-nos problemática na análise de Terrin tanto o colapso ou a «desarticulação» ${ }^{4}$ da religiosidade popular tradicional que ele dá por certo, como o «desvio» dela na direção de uma nova religiosidade, mais ampla que cobre movimentos tão diferentes como o movimento carismático e a New Age, ainda que ligados pelo desejo de um contato direto com o mundo do sagrado.

Preferimos retornar à piedade popular tradicional, vista, porém, não mais como algo próprio das classes pobres, mas como fenômeno «transversal $\rangle^{5}$ de todo o povo de Deus onde convergem, ricos e pobres, pessoas do mundo rural e do mundo urbano.

Para Giacomo Panteghini (1996), a religiosidade popular «não está acabando, não é um fóssil a ser mantido nos museus do folclore, mas uma realidade viva e vital, um organismo capaz de auto-munir-se diante das agressões externas». ${ }^{6}$ Em geral, reconhece-se a esse fenômeno uma grande vitalidade e uma recuperação numa tendência contrária ao desaparecimento do sagrado preconizado pelos sociólogos nos anos 70 do século XX. ${ }^{7} \mathrm{O}$ revival das peregrinações aos santuários de todo o mundo demonstra isso; a atenção a ela por parte do CELAM o comprova; o próprio Diretório sobre piedade popular e liturgia (2002) pressupõe isso, pois de nada valeria dedicar um símile robusto documento se não dissesse respeito a um fenômeno vital e de vasta extensão na Igreja.

Ao contrário, em 1987, um professor da Universidade de Buenos Aires, Juan Carlos Scannone, elogia a «valorização teológica» da piedade popular como «sinal dos tempos da Igreja atual». Tal valorização consiste numa dúplice operação: de um lado reconhece-se o povo como «sujeito» da cultura popular na qual encarna-se a fé, de outro admite-se uma «teologia popular» que deverá ser colocada em relação com a teologia científica. ${ }^{8}$ Res-

\footnotetext{
${ }^{4}$ L.A. Gallo, «La pietà popolare in America Latina», in Rivista Liturgica 89(2002), 982.

${ }^{5}$ I. Schinella, Cattolicesimo e pietà popolare. Una sfida per il terzo millennio, Napoli 2007, 31.

${ }^{6}$ G. Panteghini, La religiosità popolare. Provocazioni culturali ed ecclesiali, Padova 1996, 5.

${ }^{7}$ «Dopo le critiche acerrime della teologia protestante e la fine decretata dai sociologi e dai teologi della secolarizzazione, sembrava che la "religione" specie nella forma popolare non dovesse essere guardata che con disprezzo e con diffidenza. Invece, motivi sociologici e pastorali hanno portato alla ribalta negli anni '70 il tema della religione popolare. In particolare si è giunti alla convinzione che religioso e secolare non sono in rapporto di evoluzione, ma dimensioni diverse della realtà» (S. de Fiores, Maria nella teologia contemporanea, Roma 31991, 339).

${ }^{8}$ Scannone, «Religiosità popolare, sapienza del popolo e teologia popolare», in Communio n. 95(1987), 32.
} 
ta, contudo, que o aporte da teologia do povo consistirá na «característica sabedoria de vida, isto é, na sua proximidade e conexão mais profunda com a existência humana quotidiana, com a cultura própria, com a práxis e com a realidade histórica». ${ }^{9}$

Não surpreende que Ignazio Schinella, fazendo eco a João Paulo II, ${ }^{10}$ possa ter escrito como conclusão de um estudo seu:

O catolicismo popular e a sua vivência, a piedade popular, são um verdadeiro e autêntico tesouro precioso do povo de Deus e a primeira forma de inculturação da fé. ${ }^{11}$

\section{2.exercícios piedosos ou espressões culturais?}

Reconhecemos que a Igreja percorreu um longo caminho desde a época imediatamente anterior ao Concílio Vaticano II até os nossos dias. Ela passou da desconfiança em relação à piedade popular a uma aceitação das suas expressões no âmbito eclesial («pios exercícios»), até chegar a uma atitude de valorização no contexto de uma verdadeira e autêntica cultura popular.

\subsubsection{A época da desconfiança}

A partir do humanismo de Erasmo e da reforma de Lutero considerouse com desconfiança e desprezo as formas populares, tidas como corrompidas e distantes da palavra de Deus. Tal atitude tornou-se ainda mais radical e mordaz com o advento do iluminismo que submeteu a religião popular ao julgamento da razão. Passa-se, também no âmbito católico, a uma posição agressiva e intolerante verso as expressões de religiosidade popular. A tese de Gabriele De Rosa ${ }^{12}$ documenta uma posição muitas vezes repressiva ou ao menos restritiva em relação às supostas aparições e, em geral, às outras expressões típicas do povo. Na primeira parte do século XIX, os bispos de vários lugares, em particular no Meridião, proíbem atos extra-litúrgicos muito queridos ao povo.

Alguns liturgistas, às vésperas do Vaticano II, interrogam se não é o caso de «eliminar», em nome da autosuficiência da liturgia, as antigas expres-

\footnotetext{
${ }^{9}$ Scannone, «Religiosità popolare», 43.

${ }^{10}$ A piedade popular é um «vero tesoro del popolo di Dio»: Giovanni Paolo II, Omelia a La Serena (Chile), in Insegnamenti di Giovanni Paolo II, X/1 (1987), Città del Vaticano 1988, 1078.

${ }^{11}$ Schinella, Cattolicesimo e pietà popolare, 218.

${ }^{12}$ G. De Rosa, Vescovi, popolo e magia nel Sud, Napoli 1971; Id., Chiesa e religione popolare nel mezzogiorno, Bari 1978; Id., La religiosità popolare. Storia, teologia, pastorale, Roma 1981.
} 
sões da piedade popular, consideradas «não necessárias» e «provisórias» ou até mesmo «secundárias, se não inúteis, criadoras de obstáculos e incômodas».

\subsubsection{A fase da aceitação}

Sem dúvida, a posição do concílio Vaticano II é diversa, pois reafirma a legitimidade e a utilidade dos pios exercícios (LG 67), ainda que não faltem advertências a evitar os riscos da «vã credulidade» e do «estéril e transitório afeto» (LG 67). É preciso aguardar a exortação apostólica Marialis cultus, para darmos um passo a mais rumo a uma nova impostação sobre a renovação litúrgica e dos exercícios de piedade. Preciosos e inovadores os princípios estabelecidos pela $\mathrm{MC}$ para a renovação do culto mariano e, em particular, dos pios exercícios, sobretudo a orientação antropológica e cultural bem ilustrada e convincente (MC 25-37). Infelizmente a aplicação ao terço, ao menos parcialmente, foi evitada, dando a impressão de uma incoerência entre os princípios excelentes e as realizações não tão bem sucedidas.

Um decisivo input aconteceu por volta dos anos Setenta com os estudos realizados por autores de ostentada cultura marxista que chamaram a atenção sobre a realidade da religião popular como componente da cultura do povo, a ser respeitada evitando qualquer intervenção repressiva capaz de modificar-lhe as expressões. Infelizmente, a apresentação da religiosidade popular como «religião das classes subalternas» em oposição aquela das classes dominantes, produziu a rejeição em bloco destes estudos cheios de ideologia de esquerda.

\subsubsection{O momento da valorização}

A verdadeira retomada eclesial da piedade popular aconteceu com os bispos da América Latina que no Sínodo de 1974 (ou 70) chamaram a atenção para esta realidade muito vital. Suas intervenções estão presentes na exortação apostólica pós-sinodal Evangelii nuntiandi (1975), onde Paulo VI exorta a «ser sensíveis» à «realidade tão rica e vulnerável» que prefere chamar de «piedade popular», a «saber colher as suas dimensões interiores e os seus inegáveis valores» (EN 48).

João Paulo II move-se de forma decidida desde o início do seu pontificado nessa perspectiva cultural na definição e interpretação da piedade popular. Na sua primeira viagem pastoral, ao México, em janeiro de 1979, esclarece, no santuário de Zapopan, as atitudes a serem assumidas em relação a tal realidade: 


\begin{abstract}
Esta piedade popular não é necessariamente um sentimento vago, carente de sólida base doutrinal, como se fosse uma forma inferior de manifestação religiosa. Quantas vezes é, ao contrário, a verdadeira expressão da alma de um povo tocado pela graça e forjado pelo encontro feliz entre a obra de evangelização e a cultura local. ${ }^{13}$
\end{abstract}

O Papa Wojtyla estava convencido de que entre o cristianismo e a cultura existe «um nexo orgânico e constitutivo» ${ }^{14}$ e este nexo se aplica também à cultura popular enquanto visão da vida e conjunto de valores vividos. ${ }^{15}$

Um passo significativo na direção da valorização da piedade popular foi realizado pelo Diretório sobre piedade popular e liturgia, publicado em 2002 pela Congregação para o culto divino e a disciplina dos sacramentos. ${ }^{16}$ Aberto com uma carta de João Paulo II que exorta os bispos a assumir «em relação a religiosidade popular uma atitude positiva e encorajadora». ${ }^{17}$

Além da precisão da diferença entre piedade popular e religiosidade popular ${ }^{18}$ o elemento novo do Diretório é a relação da piedade popular com a cultura popular, o documento fala de «fusão harmônica da mensagem cristã com a cultura de um povo, que muitas vezes verifica-se nas manifestações da piedade popular»; e acrescenta que diversas vezes trata-se de uma «fusão tão profunda que os elementos próprios da fé cristã tornam-se elementos integrantes da identidade cultural de um povo. Veja-se, por exemplo, a piedade verso a Mãe do Senhor» (DPPL 63). Citando uma frase do então card. Ratzinger, o Diretório afirma que

\footnotetext{
${ }^{13}$ Giovanni Paolo II, Omelia nel santuario di Zapopan, 30 gennaio 1979, in Insegnamenti di Giovanni Paolo II, Città del Vaticano 1979, II, 293.

${ }^{14}$ Giovanni Paolo II, Discorso all’Unesco, 2 giugno 1980, in La Traccia 6(1980) 474.

${ }^{15}$ B. Testa, «La religiosità popolare nel magistero di Giovanni Paolo II», in Communio n. 95(1987), 55.

${ }^{16}$ Congregazione per il culto divino e la disciplina dei sacramenti, Direttorio su pietà popolare $e$ liturgia, Principi e orientamenti, Città del Vaticano 2002 (citaremos de agora em diante com a sigla DPPL).

${ }^{17}$ Giovanni Paolo II, Dal Messaggio all'assemblea plenaria della Congregazione per il culto divino e la disciplina dei sacramenti, in Direttorio su pietà popolare e liturgia, n. 5, p. 9.

18 «La locuzione "pietà popolare" designa le diverse manifestazioni cultuali di carattere privato o comunitario che, nell'ambito della fede cristiana, si esprimono prevalentemente non con i moduli della liturgia, ma nelle forme peculiari derivanti dal genio di un popolo o di una etnia e della sua cultura» (DPPL 9). «La realtà indicata con la locuzione "religiosità popolare" riguarda un'esperienza universale: nel cuore di ogni persona, come nella cultura di ogni popolo e nelle sue manifestazioni collettive, sempre è presente una dimensione religiosa. La religiosità popolare non si rapporta necessariamente alla rivelazione cristiana» (DPPL 10).
} 
a religiosidade popular é a primeira e fundamental forma de «inculturação» da fé, que deve continuamente deixar-se orientar e guiar pelas indicações da liturgia, mas que, por sua vez, fecunda a fé a partir do coração. ${ }^{19}$

A impostação cultural está cheia de conseqüências que vão daquela tratada pelo card. Ratzinger acerca da recíproca influência entre piedade popular e liturgia até aquelas indicadas por Clodovis Boff:

A piedade popular não pode ser considerada apenas como um cristianismo "de verniz" ou "superficial", nem como um cristianismo tão-somente "preparatório" à fé verdadeira, nem ainda como um cristianismo "fragmentário" ou, pior ainda, "inferior". Não; tomado no conjunto, trata-se antes de um cristianismo inteiro e verdadeiro, ainda que deficiente ou imperfeito. Nele é garantida a centralidade substancial de Cristo, embora esta apareça aí em parte desfocada, por causa da importância muitas vezes exagerada do culto dos santos, especialmente da Virgem Maria. A piedade popular é, na verdade, uma forma de inculturação do cristianismo, enquanto encarnado na cultura popular, como reconhece o próprio Diretório sobre piedade popular e liturgia (n. 91). ${ }^{20}$

Não tem muito significado falar de «diferença abissal» entre piedade popular e religiosidade popular, porque a primeira se move no âmbito da fé cristã, enquanto que a segunda não seria necessariamente relacionável à revelação cristã. Estando no âmbito cultural sabemos que a fé não pode prescindir da cultura, porque - como diz João Paulo II - «uma fé que não torna-se cultura é uma fé não plenamente acolhida, não pensada inteiramente, não vivida fielmente». ${ }^{21}$ Como a cultura implica a relação dos seres humanos com o tempo e com o espaço, também as expressões religiosas (peregrinações, orações repetitivas ou numéricas e outras práticas de devoção) são assumidas e oportunamente modificadas pela piedade popular iluminada pela revelação bíblica. A fé em estado puro não existe, mas sempre tem relação com a religião com os seus mitos e seus ritos, seus valores e limites, suas relações espaço-temporais.

\footnotetext{
${ }^{19} \mathrm{~J}$. Ratzinger, Commento teologico, in Congregazione per la dottrina della fede, Il messaggio di Fatima, Città del Vaticano 2000, 35.

${ }^{20}$ C. Boff, Mariologia social. O significado da Virgem para a Sociedade, São Paulo 2006, 552.

${ }^{21}$ Giovanni Paolo II, Ai partecipanti al Congresso nazionale del Movimento ecclesiale di impegno culturale (MEIC), 16 gennaio 1982.
} 
Outra conseqüência: tratar da devoção mariana ou da piedade mariana popular fora do contexto da cultura popular significa colocar-se numa posição defensiva, malévola e mortificante, que não compreende como a cultura implica concepções antropológicas que comandam as expressões e conferem a elas sentido. Abolir as expressões sem mudar a antropologia de base demonstra-se uma obra pastoral infrutífera, porque pretende purificar uma água potencialmente poluída sem purificar a sua fonte.

Sendo assim, o caminho a ser percorrido é obrigatório: é preciso examinar a piedade mariana no contexto da cultura popular para apurar como inserir nela a figura bíblica de Maria e tentar uma válida mariologia popular.

\section{A Figura de Maria no horizonte da cultura popular}

\subsection{Características predominantes da cultura popular}

Damo-nos conta que a questão alarga-se, ainda mais, pois inclui as principais zonas de desenvolvimento da cultura popular começando pela América Latina, passando pela Europa, pelo Meridão da Itália, até chegarmos a Marchesato di Crotone sobre a qual o Pe. Raffaele Malena realizou uma vasta pesquisa, que culminou com sua tese de mais de 700 páginas, defendida no Marianum em 1981. ${ }^{22}$ Limitar-nos-emo a propor, seguindo Clodovis Boff, «os traços mais marcantes da piedade popular», com aplicações à devoção mariana.

\subsubsection{Sentimento ou via cordis.}

Diferentemente da cultura racionalista, a popular sublinha o sentimento ou as emoções, numa palavra: o coração. Isto vale, também, para a relação devota com Maria, que pode ser assim descrita:

Em relação à Maria Santíssima, a piedade do povo católico é verdadeiramente "visceral" ou "entranhada". Os devotos tratam Maria com extremo carinho. Falam em termos de «Mãe querida» e mesmo de «Mãezinha do céu». Outros modos de falar, que denotam intimidade, são o uso do diminutivo [...]. O mesmo vale para o uso do pronome «minha» $[\ldots]$. Há uma espontaneidade e uma since-

\footnotetext{
${ }^{22}$ R. Malena, Devozione mariana e folclore nel Crotonese, Tesi di laurea in teologia con specializzazione in mariologia, Pontificia Facoltà teologica Marianum, Roma 1981, pp. XLIV-684.
} 
ridade verdadeiramente comoventes nos sentimentos da piedade que o povo humilde vota à Mãe de Cristo. ${ }^{23}$

\subsubsection{Exuberância.}

Esta super-abundância devocional manifesta-se com «hinos, litanias, fogos de artifício e cores», com as festas que já possuem certo excesso e com atos de generosidade penitencial e nas ofertas. Compreende-se a crítica aos exageros da piedade do povo, mas a crítica desconhece as raízes de tais exageros, que é o amor. A lingua amoris (Agostinho) é exagerada para os estranhos, para quem não se expressa por meio dela. Todo amor intenso foge do controle da razão e parece atribuir aos santos o amor reservado a Deus; na realidade as diferenças existem nestas mesmas expressões.

\subsubsection{Expressividade.}

A religião popular não é intimista mas ostensiva: manifesta com gestos visíveis e tangíveis os sentimentos. Não é de maravilhar-se se «o povo usa numerosos sinais e gestos, como tocar as imagens, beijá-las, oferecer flores e ex-votos, acender velas, fazer peregrinações e procissões, andar de joelhos, usar medalhas, fitas e escapulários, levar vestes especiais etc.». ${ }^{24}$

\subsubsection{Vitalidade.}

É comum dizer que a religião do povo «é muito concreta, "encarnada" e como que empastada nos problemas da vida cotidiana». As pessoas pedem à Virgem «"proteção frente às múltiplas ameaças que tem de enfrentar em relação à saúde, à segurança, à solução de problemas afetivos (namoro, paz doméstica etc.), à libertação dos vícios (alcoolismo, drogas etc.), ao desemprego, e assim por diante»». ${ }^{25}$ Da análise de um livro dos peregrinos do santuário de Dinnammare (Messina) resulta que o povo pede à Maria pricipalmente graças espirituais, depois graças ligadas a relacionamentos e, por fim, graças materiais. ${ }^{26}$

\footnotetext{
${ }^{23}$ Boff, Mariologia social, 554.

${ }^{24}$ Boff, Mariologia social, 556.

${ }^{25}$ Boff, Mariologia social, 557.

${ }^{26}$ E. Foti, Preghiere popolari alla Madonna nel santuario di Dinnammare, Tesi di laurea in teologia con specializzazione in mariologia alla Pontificia Facoltà teologica Marianum, Roma 1980.
} 


\subsubsection{Caráter maravilhoso.}

O povo tem um forte sentido do sacro natural e cósmico, portanto da trascendência de Deus e do seu poder. É muito sensível ao maravilhoso: «é o mundo das graças recebidas, dos milagres e das aparições. [...] Coloca-se essencialmente na esfera da "sobrenatureza", onde a lógica não é a do mundo ordinário, mas a do extraordinário». ${ }^{27}$ Por isso - observa C. Boff - «o povo repele instintivamente representações por demais "realistas" de Maria. Sente-se ofendido quando vê a Virgem Santíssima representada de um modo ordinário, prosaico e pauperista, como querem certos agentes pastorais intelectualizados. Pelo contrário, o povo ama imaginar Maria com traços de beleza e de riqueza supremas». ${ }^{28}$

\subsection{O universo antropológico da cultura popular da Calábria}

Além dos modos característicos da cultura popuar, interessa-nos penetrar em seu mundo orgânico, em sua concepção da vida e nos seus valores fundamentais. Uma tentaviva difícil, realizada por poucos autores, dentre os quais distinguem-se: Mons. Giuseppe Agostino, um dos primeiros a chamar a atenção eclesial verso a piedade popular; Pe. Maffeo Pretto, benemérito pelos estudos sobre a piedade e a santidade popular na Calábria; e Pe. Ignazio Schinella a partir da perspectiva teológica. ${ }^{29}$

Eles expõem este mundo cultural. Agostino de maneira mais positiva e religiosa, o Pretto de maneira mais problemática, partindo do que ele chama «uma verdadeira encruzilhada existencial da cultura popular», representado pela «experiência do destino», cujos sinais estão presentes nos provérbios e cantos regionais:

\footnotetext{
${ }^{27}$ Boff, Mariologia social, 558.

${ }^{28}$ Boff, Mariologia social, 559.

${ }^{29}$ G. Agostino, Le feste religiose nel Sud, Torino 1977; Id., «Chi è Maria per il popolo», in La Madonna 32(1984)5-6, 66-70; Id., «Pietà popolare», in NDM 1111-1122; Id., La pietà popolare come valore pastorale, Milano 1987; M. Pretto, La pietà popolare in Calabria, Cosenza 1988; Id., Santi e santità nella pietà popolare Calabria, 2. vol., Cosenza 1993; I. Schinella, «Pietà popolare: annuncio di fede ed esperienza spirituale. Un'interessante rilettura nella Chiesa di Calabria», in Rivista Liturgica 90(2003), 151-164; Id., «Il Cattolicesimo popolare oggi: ipotesi di lettura», in A. Sabatell-P. Zuppa (ed.), Il cristianesimo popolare oggi: persistenza o novità, rischio o chance?, Monopoli-Roma 2004, 13-59; Id., «Fondazione e lettura teologica della pietà popolare», in Rassegna di teologia 45(2004), 361-379; Id., «La Madre di Gesù associata al mistero della Croce e della risurrezione secondo la pietà popolare», in S. De Fiores - G. Strangio - E. Vidau (ed.), Popolo sacerdotale in cammino con Maria, Atti del XVIII Colloquio internazionale di mariologia, GeraceSan Luca (RC), 13-15 ottobre 2005, Roma 2008, ......
} 


\begin{abstract}
Para além das explicações parciais emerge continuamente na cultura popular o sentimento da sorte, do destino, entidades impessoais tidas como causa dos acontecimentos mais absurdos possíveis. É a experiência do inevitável, do arbitrário inserida na trama da vida que está nas mãos de forças estranhas e superiores; é a presença de um absurdo malvado que dentro do próprio ser e agir, golpeia e parece dominar o desenrolar dos acontecimentos. ${ }^{30}$
\end{abstract}

Deste cenário, herança da moira, do Destino do helenismo, derivam duas vias: uma (muito rara) que desemboca no fatalismo e no ateísmo prático, a outra (mais comum) que conduz ao Deus cristão da providência, criador e protetor dos humanos, ameaçados pela precariedade da vida. A dimensão da impiedade manifesta-se na blasfêmia contra Deus, Nossa Senhora e os santos, «com palavras ofensivas, com atitudes de vingança como: não ir à igreja, desprezar as imagens sacras»; trata-se, porém, de «uma variável derivada e dependente da piedade; não tendo, no mundo popular calabrês, autonomia, nem visão do mundo, nem lugar e ritos próprios»».

A experiência de Deus e a confiança na sua providência expressam-se em numerosos cantos da Calábria e nas frases freqüentes: "Ciò che Dio vuole», «Dio sa» e «Bettu Ddeu».

Tudo isto é expresso por estupendas orações onde desaparece completamente o sentimento sombrio do fatalismo e aparece a serena confiança no amor de Deus, de Cristo, de Nossa Senhora, que são capazes de trasformar até mesmo a dor e abrir a vida a um otimismo vitorioso. ${ }^{32}$

A providência de Deus concretiza-se na figura de Cristo, «figura central do catolicismo popular na Calábria». Os mistérios da sua vida desde o Natal, passando pela Paixão, e até a Páscoa são celebrados pelo povo durante todo o ano. Em particular «a centralidade de Cristo é expressa numa outra série de contos populares sobre quando Cristo caminhava pelo mundo e encontrava-se com pessoas comuns; é um autêntico evangelho popular». ${ }^{33}$

A aceitação do evangelho implica a acolhida dos seus valores e comportamentos virtuosos. Devemos reconhecer a visão previdente do grande escritor calabrês contemporâneo, Corrado Alvaro (1895-1956), que fez e-

\footnotetext{
${ }^{30}$ M. Pretto, Santi e santità nella pietà popolare Calabria, Cosenza 1993, I, 18.

${ }^{31}$ Pretto, Santi e santità nella pietà popolare Calabria, 26.

${ }^{32}$ Pretto, Santi e santità nella pietà popolare Calabria, 24.

${ }^{33}$ Pretto, Santi e santità nella pietà popolare Calabria, 22.
} 
mergir nitidamente, nos seus romances e escritos, vários valores, além dos riscos e desvalores, da cultura mediterrânea: o sentido da honra, da justiça, da liberdade, o sentimento de aceitação do fatalismo diante dos tristes eventos da vida, a importância suprema da família, a grande importância da ideia da autoridade, o protesto contra as injustiças, o amor à liberdade, o sentimento de amizade, a importância do feminino... ${ }^{34}$ Alvaro personifica alguns desses valores nos seus romances: a justiça em Gente in Aspromonte (Antonello), a liberdade em L'uomo è forte (Dale), o amor em Belmoro (Belmoro).

$\mathrm{Na}$ verdade, Alvaro demonstra uma consciência atenta, defendendo e exaltando, em seus romances e escritos, os valores da justiça, da liberdade e da responsabilidade, amor e solidariedade. Em seu personagem, ele apresenta o grande valor da liberdade. Está convencido que cada homem deve assumir a sua própria responsabilidade diante da história ${ }^{35}$. O escritor sabe que nada contra-corrente $\mathrm{e}$ nota que «uma das características marcantes da vida moderna é a perda do sentido de responsabilidade» ${ }^{36}$. D'outra parte, ele não pode renunciar à liberdade, «condição essencial do homem, que o distingue do animal $»^{37}$. Alvaro, além disso, dedica, por diversas vezes, sua atenção à dignidade da mulher, segundo a práxe primitiva do cristianismo. Ela não é um ser diabólico, mas «aparece, sempre como o mundo mais íntimo e querido do homem, a mãe, a irmã, a noiva, a esposa $»^{38}$. Sensível à situação da mulher "escrava da necessidade», Alvaro nota com íntima solidariedade: «é, talvez, o proletariado e o trabalho braçal mais indefeso que exista» ${ }^{39}$. O escritor atribui à mulher a energia que conduz o homem à sua autoconsciência. Na realidade «a mulher é o personagem mais importante e mais autêntico da Calábria. É, ao mesmo tempo, o luxo de uma natureza escabrosa, reduzida a tal situação miserável pelos homens $»^{40}$.

\footnotetext{
${ }^{34}$ O. Martucci, Una civiltà che scompare. Il mondo di Corrado Alvaro, Bamberg 1970, 167-183.

${ }^{35}$ Cf. C. Alvaro, Ultimo diario (1948-1956), Milano 1959, 198.

${ }^{36}$ Alvaro, Ultimo diario, 123.

${ }^{37}$ Alvaro, Ultimo diario, 219-220.

${ }^{38}$ C. Alvaro, Il nostro tempo e la speranza. Saggi di vita contemporanea, Milano 1959, 14.

${ }^{39} \mathrm{C}$. Alvaro, «Le donne che portano pesi», in Il nostro tempo e la speranza, 12-15.

${ }^{40}$ C. Alvaro, Ultimo diario (1948-1956), 124. A inteira citação está em S. De Fiores, Itinerario culturale di Corrado Alvaro, Soveria Mannelli 2006, 48.
} 


\subsection{Imagem folclórica de Maria}

Somente mergulhando no imenso mar de contos, poesias e tradições populares calabrês sobre a Mãe de Jesus, é possível compreender a sua figura na cultura popular.

L. Lombardi Satriani, em ótica antropológica, iniciou esse discurso, numa intervenção na XIII Convenção nacional de reitores de santuários italianos (1977): a «Madonna folklorica» aparece com dimensões familiares, aprendiz, mas também mediadora junto ao Filho irado, adolorada que ajuda na superação do negativo (a morte...), que opta pelos pobres porque não comprometida com os desfrutadores. ${ }^{41}$

Alargando a perspectiva o arcebispo G. Agostino infere cinco intuições teológicas da piedade mariana popular:

a) Maria é cultuada como uma presença viva;

b) como presença materna e como mediadora singular e universal;

c) participante do sofrimento humano;

d) como mãe ela é canal de comunhão;

e) modelo da existência cristã, projeto daquilo que devemos ser, ícone daquilo que queremos ser. ${ }^{42}$

O mesmo autor reafirma a imagem folclórica de Maria retratando-a como Mãe de Cristo, mãe potente e misericordiosa; a «diversa» de nós pecadores, porque toda santa, imagem ideal do ser humano redimido por Deus, verdadeira obra de arte da graça; aquela que viveu conosco o lado obscuro e trágico do sofrimento, da pobreza... por isso, muito próxima ao povo que «pressente» e «experimenta» sua proximidade como conforto, estímulo e esperança. $^{43}$

Por tudo isto, Maria de Nazaré é cultuada na universalidade da natureza humana e na concretude da história de cada indivíduo. A piedade mariana do povo sempre cultivou, com verdadeira simplicidade os dois extremos da vida da Mãe de Deus: diversa de nós, mas, ao mesmo tempo, como nós; nossa irmã e mãe, única e irrepetível.

\footnotetext{
${ }^{41}$ L.M. Lombardi Satriani, «Il canto religioso specialmente mariano nel contesto della cultura popolare», in La Madonna 26(1978)1-2, 21-31.

${ }^{42} \mathrm{G}$. Agostino, «Chi è Maria per il popolo», in La Madonna 32(1984)5-6, 66-70. Altre acute osservazioni in Id., «Pietà popolare», in Nuovo Dizionario di Mariologia, Cinisello Balsamo 1985, 1111-1122.

${ }^{43}$ Cf. G. Agostino, «Pietà popolare», in Nuovo Dizionario di Mariologia, 1111-1116.
} 
Francesco Tortora, bispo de Gerace-Locri, na admirada carta pastoral Per una devozione popolare autentica verso la Madre di Dio (1981), traça com profunda análise as características do culto de Nossa Senhora para o povo de Locride: sentido do sacro, referência à Trindade, extrema proximidade de Maria, afetuosa insistência na súplica, presença de Maria no mistério pascal, sensibilidade à beleza da Virgem, peregrinações e celebrações da festa, corroborando cada parágrafo com cantos ou gestos de piedade mariana popular. ${ }^{44}$

É óbvio que pertence à teologia a tarefa de confrontar esta imagem popular de Maria com a editio typica dela oferecida pelo Evangelho, acrescentando ou retirando o que estiver em contraste com essa. Quanto às expressões devotas, o Diretório sobre piedade popular e liturgia, dedica o capítulo V à «veneração à Mãe do Senhor» (nn. 183-207). Aí são estabelecidos alguns princípios da piedade mariana, com particular referência à liturgia, cume e fonte da vida do povo de Deus (nn. 183-186); são examinados os tempos dos pios exercícios marianos (nn. 187-191) e alguns pios exercícios recomendados pelo Magistério (nn. 192-207).

Compete também à teologia elaborar uma «mariologia popular» que insira a autêntica figura da Virgem nas raízes da tradição eclesial e da cultura dos vários povos: um trabalho de fundamentação bíblico-patrística, de justificação teológica, de inculturação e de tradução vital-salvífica.

\section{Rumo à elaboração de uma mariologia popular}

Apesar das tentativas de apresentação de uma mariologia popular, sobretudo na América Latina, ${ }^{45}$ sentimos a necessidade de traçar alguns crité-

\footnotetext{
${ }^{44}$ F. Tortora, Per una devozione popolare autentica verso la Madre di Dio, Leumann 1981.

${ }^{45}$ Uma primeria interessante e explícita elaboração de uma mariologia popular latinoamericana foi realizada pelo jesuíta Antonio González Dorado no ensaio De María conquistadora a María liberadora. Mariología popular latino-americana, Santander 1988, pp. 142. Ele parte da autêntica teologia presente na religiosidade popular e da complexa referência que ela tem com a Virgem Maria. Em seguida, distingue três etapas que históricas: a) Maria conquistadora veiculada pelos conquistatodes espanhóis (uma mariologia agressiva e negativa em relação à evangelização); b) Maria dos oprimidos que inaugura em Guadalupe um processo de incorporação de Maria na cultura ameríndia ou latinoamericana (alguns índios repetiam diantes da imagem impressa no manto de Juan Diego: «Noble indita, noble indita, Madre de Dios! Noble indita! Toda nuestra!»); c) Maria libertadora que coincide com a independência política do continente, mas que hoje projeta-se na dinâmica das transformações das estruturas, libertando também das deficiências da cultura popular tradicional. Por fim, é preciso tentar uma síntese da teologia mariana popular, fundada sob o núcleo de compreensão constituído pelo binômio profundamente afettivo «Mãe nossa-filhos» dentro da trilogia «opressão-machismo-experiência rural» mas de maneira a evitar a mariolatria, a desvalorização da mulher e o fatalismo.
} 
rios e orientações que sirvam para a sua elaboração e, ao mesmo tempo, sejam úteis para a catequese e para a ação pastoral.

Interrogar-nos-emos sobre quatro questões: o ponto de partida, a relação com a Palavra de Deus, a harmonização com a liturgia, o enlace com a vida.

\subsection{O ponto de partida: a realidade viva de Maria}

Por onde iniciar? Pela Maria celeste ou pela Maria terrena? Pela Bíblia ou pela cultura popular?

O círculo hermenêutico, que substituiu o método dedutivo escolástico, nos conduz com segurança à cultura e à vida. Devemos, portanto, partir da cultura popular, do seu universo simbólico e da sua antropologia, onde percebemos como o povo vê Maria e se relaciona com ela.

A atitude de respeito, envolvimento, escuta do povo deve conduzirnos a valorizar suas intuições sobre Maria. É uma consequência do «sensus fidelium», cujo papel de promover uma firme adesão às verdades de fé, manifestou-se na definição dos dogmas marianos da Imaculada e da Assunção.

A intuição central do povo sobre Maria é sem dúvida a de concebê-la na fé como uma pessoa viva, glorificada, dotada de poder e bondade materna e, portanto, capaz de intervir nos acontecimentos humanos. Em outras palavras, o povo vê em Maria o sucesso da redenção, o triunfo da vida sobre a morte, o valor da intercessão daquela que vive a páscoa eterna de Cristo.

Daí deriva uma consequência de grande valor prático, que na Igreja latinoamericana foi assim formulada:

Uma piedade mariana puramente tipológica não tem valor formativo; é uma ilusão pastoral. Não basta afirmar: a Virgem é exemplo de fideldade à palavra, de força na dor... por isso devemos imitá-la. Se não cultivamos os laços, o amor, o afeto pela pessoa de Maria, a exigência de imitação de um protótipo é um puro imperativo categórico. Para tornar fecundo o carisma de Maria é necessário que os laços marianos (que tem a prioridade pedagógica) conduzam à atitude mariana (que tem a prioridade entitativa $)^{46}$.

A elaboração de uma «mariologia popular» deveria partir da condição escatológica de Maria na sua influência costitutiva do «fato mariano» dentro

\footnotetext{
${ }^{46}$ J. Alliende Luco, «Diez tesis sobre pastoral popular», in Equipo Seladoc, Religiosidad popular, Salamanca 1976, 122.
} 
da Igreja, para depois passar aos acontecimentos bíblicos e à sua divina maternidade: uma mariologia original, que inverte o método dos manuais.

Como observa Clodovis Boff, é preciso partir não do momento reflexivo e nem mesmo do empenho ético, mas da «relação afetiva entranhada para com a Mãe de Cristo». ${ }^{47}$ Em particular na Calábria ocorre, em primeiro lugar, estabelecer os dados emergentes da história da piedade sobre a relação com a Mãe de Jesus: as intervenções de Maria no surgir dos santuários (aparições, descobrimento de ícones ou estátuas...), a sua experiência na vida documentada das orações, cantos, promessas, a pertença dela e de Cristo a nossa região (a lenda da maga $\operatorname{Sibilla~}^{48}$ e o evangelho popular ${ }^{49}$ ). Praticamente trata-se de estabelecer o fato ou fenômeno mariano presente na história e

\footnotetext{
${ }^{47}$ Boff, Mariologia social, 584.

${ }^{48}$ «Nel tempo dei tempi, fra le aspre rocce dell'Aspromonte, in una valle dolcemente boschiva, s'ergeva un castello. Negli antri misteriosi, che si prolungavano nelle viscere dei monti, si eternavano gli echi fragorosi delle acque precipitanti nella notte degli abissi. In questo castello viveva una bellissima donna, la donna più sapiente dei tempi, detta Sibilla Cumana. Era con lei suo fratello a nome Marco. Dalla Sibilla le famiglie più illustri mandavano le figlie ad apprendere le arti e le scienze. Era come un giardino, ove i fiori più belli sbocciavano sorridenti al sole, ammiccante tra le vette.
}

[...] Allora tra le fanciulle si usava narrare i sogni della notte. Un giorno una bimba a nome Maria narrò d'aver sognato che un raggio di sole, entratole dall'orecchio destro, le era uscito per il sinistro. La Sibilla divinò il sogno. Ella capì che quella dolce creatura era destinata ad essere la madre del figlio di Dio e, presa da un impeto d'ira, volle distruggere il mezzo di tramandare l'arte, le scienze e le dottrine. Accese un gran fuoco ed ordinò alle timide bimbe di buttare alle fiamme i loro libri. Or la piccola Maria, alla quale faceva gran pena privarsene, nascose il librettino tra le vesti. La Sibilla prese ad interrogare le fanciulle, per vedere se avessero eseguito il suo volere. Giunta presso Maria, così le disse: «e tu?» e la fanciulla le rispose: «l'ho [l'aio] ». La Sibilla interpretò quella risposta come affermativa, nel senso che Maria avesse dato il libretto alle fiamme, e passò oltre. Fu così, secondo questa leggenda, che si salvò la scrittura!

[...] Passarono i secoli, il castello scomparve tra fitte boscaglie e cumuli di spine ed il sole spostò il suo corso onde lasciare nella notte eterna quel luogo maledetto. Più giù, nella valle di Polsi sorge un santuario, dedicato alla Madonna, e la gente va a salutare Maria, con pellegrinaggi infiniti a piedi e a ridosso di mulo. Ognuno le porta il dono che per voto le ha promesso. Tra i piccoli e aspri sentieri il popolo porta in trionfo il simulacro di Maria, ma, allorché la statua dovrebbe essere rivolta verso levante, in direzione del luogo ove un tempo fu il castello della Sibilla, con rapido giro voltano la «bara», in modo che l'immagine volti il tergo alla grotta. Lassù, mentre fra lo scoppio dei mortaretti, lo sparo dei fucili e l'esultanza della folla, la statua, così rivolta, entra nel santuario, corruschi cirri coprono le cime. Sembra, tra il fragore delle acque udire il lamento di Marco nell'eterna imprecazione della Sibilla Cumana. Solo un cancello di ferro tra gli sterpi secolari attesta il passato» (L.M. Lombardi Satriani-M. Meligrana, «La presenza di Cristo della cultura popolare meridionale», in I problemi di Ulisse 30[1976]n. 81, 160-161).

${ }^{49} \mathrm{Cf}$. as lendas orais sobre Jesus que percorre as estradas da Calábria no artigo citado de L.M. Lombardi Satriani-M. Meligrana, «La presenza di Cristo della cultura popolare meridionale», specie 166-175. Cf. anche P. Cappelli, Vangelo popolare. Quando Cristo si aggirava nelle nostre terre, [s.1.] 2003. 
na experiência calabrês sob a base de tantos valores acerca do argumento, ${ }^{50}$ preocupando-se, sobretudo, com seus aspectos interiores e inserido-os no complexo da cultura popular.

\subsection{O confronto com a Palavra de Deus: Evangelizar a piedade mariana popular}

Partindo da análise do fato mariano é necessário proceder ao confronto com a Palavra de Deus, norma e juízo de toda práxis eclesial. Trata-se de «evangelizar» a piedade mariana popular de modo que responda à revelação divina e torne-se cada vez mais um autêntico encontro com Cristo Salvador.

Para afastar a piedade mariana popular da tentação de isolamento, é necessário «preenche-la» da Palavra de Deus, que julga, purifica e salva. Uma atenta teologia e catequese bíblica fundamentar-se-á sob alguns elementos de importância capital.

\subsubsection{O Plano da salvação.}

A insitência sobre o desígnio divino que se atua na história da salvação é importante para evangelizar de maneira radical a cultura popular por vezes marcada pela concepção do «destino», força cega que determina a existência humana. A sua terapia é costituída pela convicção de que tudo no mundo procede da sabedoria e misericórdia do Pai, que envia o Filho ao mundo para que os seres humanos constituídos como Igreja, por obra do Espírito, retornem a ele. É o círculo salvífico pregado por Irineu e pelos padres. A contínua rereferência à história salvífica - seguindo os padres e o concílio Vaticano II - será o pano de fundo sob o qual colocar Maria e o seu culto, a fim de que assumam a sua exata proporção e finalidade.

\subsubsection{O Primado de Cristo.}

Evangelizar a religiosidade popular implica em fazê-la girar em torno de Cristo, centro do plano salvífico e da fé, que deve ser reconhecido como único salvador e mediador, princípio e fim da vida de cada cristão. É preciso insistir sobre a pessoa de Cristo misericordioso e sobre sua união imediata com os fiéis, guiando-os em direção a uma relação vital, pessoal, profunda, perseverante com ele sob o exemplo e sob a guia materna de Maria. É preci-

\footnotetext{
${ }^{50}$ Temos sorte porque foi publicado em edição italo-francese o volume bibliográfico: G.M. Viscardi-P. Lérou (ed.), La pietà popolare in Italia, t. I: Calabria, Paris-Roma 1996. Nesse precioso volume faltam algumas referências, coma a voz «Piedade popular» di G. Agostino in Nuovo dizionario di mariologia, Cinisello Balsamo 1985, 1111-1122.
} 
so direcionar as várias expressões populares «ao centro de toda sã piedade, Cristo Jesus Filho de Deus Salvador». ${ }^{51}$ Sem esquecer-se do vínculo de Cristo com a sua Igreja, comunidade de salvação através da palavra, dos sacramentos e do testestemunho. Jamais Cristo sem a Igreja.

\subsubsection{A narrativa dos evangelhos acerca de Maria.}

Após sublinhar e fundamentar na história a relação vital dos fiéis com Maria, faz-se mister demonstrar como esta baseia-se, em última análise, na Palavra de Deus. Palavra que nos apresenta a figura de Maria em sua missão e em suas atitudes profundas, suscitando afeto filial por aquela que é nossa mãe e imitação porque nosso modelo de virtude.

Cabe uma interrogação: qual é a figura bíblica de Maria?

A resposta exigiria uma ampla abordagem capaz de identificar nos estudos exegéticos mais recentes a imagem bíblica da Mãe de Jesus. Aqui contentarnos-e-mos com uma classificação de tais estudos a partir de duas orientações: a sincrônica e a diacrônica.

a) A orientação sincrônica - uma tendência contemporânea considera Maria como um fragmento no qual está refletida toda a fé: um compêndio ou síntese de toda a revelação bíblica. Como, de fato, afirma Ignace de la Potterie,

uma aquisição muito importante para a exegese moderna é ter consierado que o mistério de Maria constitui-se, de certo modo, numa síntese de toda a revelação precedente do povo de Deus... e na sua pessoa concreta ante-

\footnotetext{
${ }^{51}$ Citamos por completo o texto pastoral de João Paulo Il aos responsáveis dos santuários marianos: «Bisognerà curare con grande attenzione e zelo la pastorale nel santuari mariani, mediante una liturgia appropriata e viva, mediante la predicazione assidua e di salda catechesi, mediante la preoccupazione per il sacramento della penitenza e la depurazione prudente di eventuali forme di religiosità che presentino elementi meno adeguati.

Bisogna approfittare pastoralmente di queste occasioni, magari sporadiche, dell'incontro con anime che non sono sempre fedeli a tutto il programma di una vita cristiana, ma che qui vengono guidate da una visione alle volte incompleta della fede, per cercare di condurle al centro di una salda pietà, Cristo Gesù, Figlio del Dio Salvatore.

In questo modo la religiosità popolare andrà perfezionata, quando sia necessario, e la devozione mariana acquisterà il suo pieno significato in un orientamento trinitano, cristocentrico ed ecclesiale, come così a proposito insegna la esortazione Marialis cultus (nn. 25-27).

I sacerdoti incaricati dei santuari, coloro che guidano ad essi i pellegrini, li invito a riflettere ponderatamente sul grande bene che possono fare al fedeli, se sapranno porre in opera un sistema di evangelizzazione appropriato.

Non sprecate alcuna occasione di predicare Cristo, di chiarire la fede del popolo, di irrobustirla, aiutandolo nella sua via verso la Trinità. Sia Maria il cammino» (Omelia nel santuario di Zapopan, 31-1-1979).
} 
cipa-se aquilo que realizar-se-á para todo o novo povo de Deus, que é a Igreja ${ }^{52}$.

Bruno Forte cunha uma feliz fórmula para exprimir tal caráter sintético de Maria: «ícone de todo o mistério cristão» ${ }^{53}$.

Parece-nos exato denominar a Mãe do Senhor: «microhistória da salvação», pois «nela encontram-se os modos de agir divino e nela encontra-se a resposta exemplar às intervenções de Deus na história da salvação». ${ }^{54} \mathrm{Em}$ Maria, ápice do AT que abre-se à acolhida de Cristo, convergem as vias de Deus, a sua lógica supraracional, as leis histórico-salvíficas expressas por Ele na revelação: promessa-cumprimento, kenose-exaltação, concentração na pessoa-dilatação na comunidade, opção pelos pobres e pela mulher... Todas essas são vias que advindas do AT convergem em Maria, chegam à plenitude em Cristo e comunicam-se à Igreja.

Alberto Valentini, autor de um recente volume sobre Maria segundo as Escrtturas, confirma tal impostação histórico-salvífica:

a figura de Maria está ligada intimamente à história da salvação que culmina em Cristo e cresce com a manifestação luminosa do seu mistério. Uma adequada compreensão da mãe de Jesus exige tal contexto: só assim é possível recuperar sua imagem bíblica, na qual revela-se a imagem autêntica de Israel e da Igreja segundo o projeto de Deus.

Em tal âmbito emerge a sua valência típica se comparada com os demais discípulos do Senhor. A função exemplar da mãe de Jesus em relação à existência cristã. ${ }^{55}$

Inserida na história da salvação, Maria «é tipo ideal da comunidade da aliança; é a mulher que colocou a vida a serviço do povo de Deus, por meio da sua fidelidade à aliança». Por sua colaboração na encarnação do Verbo e por sua presença na hora do Filho, Maria é «costituída e entregue pelo próprio Jesus

\footnotetext{
${ }^{52}$ I. de la Potterie, Maria nel mistero dell'alleanza, Genova 1988, 15 e 256.

${ }_{53}^{5}$ B. Forte, Maria, la donna icona del mistero, Cinisello Balsamo 1988, 103.

${ }^{54}$ S. De Fiores, Maria Madre di Gesù. Sintesi storico-salvifica, Bologna 1992, 47-52; Id., «Maria microstoria della salvezza. Verso un nuovo statuto epistemologico della mariologia», in Theotokos numero 0(1992), 7-22; Id., «Maria microstoria della salvezza», in G. Bortone (ed.), Maria nella Bibbia dalle prefigurazioni alla realtà, XXIV Corso biblico, L'Aquila 2004, 263-289; Id., «Microstoria della salvezza», in Maria. Nuovissimo dizionario, Bologna 2006, 1143-1169.

55 A. Valentini, Maria secondo le Scritture. Figlia di Sion e Madre del Signore, Bologna 2007, 27-28.
} 
como mãe do "discípulo amado", figura de todos os discípulos». Ela «é um dom do Senhor, oferecido a todo fiel» para ser acolhido na própria vida. ${ }^{56}$

b) A orientação diacrônica - alguns exegetas demostram-se sensíveis à evolução de Maria em relação a Cristo seu Filho, distinguindo as várias fases da sua vida, particularmente sua passagem de mãe à discípula, membro da comunidade de pentecoste. Entre eles, distinguem-se F. Braun e R. Guardini, extremamente atentos às etapas da história terrena da Virgem de Nazaré. ${ }^{57}$ A. Serra segue o critério basilar de verificar «os autores do NT que falam da mãe de Jesus dispondo-os segundo a ordem cronológica aceita pela crítica hodierna», convencido que

os testemunhos mariológicos do NT, considerados a partir da ordem do tempo, oferecem uma grandiosa vantagem. Consentindo a percepção do modo e da progressão com a qual os autores inspirados tomaram consciência da pessoa e do papel de Maria dentro de toda a história da salvação. ${ }^{58}$

No âmbito da teologia bíblica, o critério diacrônico vem sendo assumido como chave interpretativa da figura de Maria no NT, particularmente por traçar o seu caminho de fé ou o «itinerário místico» ${ }^{59}$ ou por deter-se nas várias fases do «Itinerário discipular de Maria»: da sua fé em Cristo anunciado, à sua penetração progressiva no mistério de Cristo, passando pelo seu tornar-se discípula de Cristo (Marcos), ou melhor, «proto-discípula» dele (João), até sua fé pós-pascal no horizonte da primeira comunidade de Jerusalém. ${ }^{60}$ Discernindo a passagem de Maria de mãe à discípula de Deus para ser, por fim, revelada pelo Cristo crucificado como mãe do discípulo amado.

Ambas correntes exegéticas confirmam a fé bíblica da Igreja reconhecendo que a Mãe do Senhor:

1. participa do mistério fundamental da encarnação e do mistério pascal de Cristo, núcleo central da fé, porque Mãe fiel e responsável pelo Verbo encarnado por obra do Espírito Santo e mãe dos discípulos amados;

\footnotetext{
${ }^{56}$ Valentini, Maria secondo le Scritture, 414-415.

${ }^{57}$ Cf. F.M. Braun, La Mère des fidèles. Essai de théologie johannique, Tournai-Paris 19542; R. Guardini, Die Mutter des Herrn. Ein Brief und darin ein Entwurf, Würzburg 1955. Trad. ital.: La Madre del Signore. Una lettera con abbozzo di trattazione, Brescia 1989.

${ }^{58}$ A. Serra, «Bibbia», in Nuovo dizionario di mariologia, Cinisello Balsamo 1985, 232.

${ }^{59}$ S. De Fiores, «Maria», in L. Borriello-E. Caruana-M.R. Del Genio-N. Suffi (ed.), Dizionario di mistica, Città del Vaticano 1998, 773-775.

${ }^{60}$ S. De Fiores, «Discepola», in Maria. Nuovissimo Dizionario, Bologna 2006, I, 495-505.
} 
2. é exemplo de virtude, pois participa do grupo dos Pobres de $Y H W H$ que aguardam e acolhem exemplarmente a salvação, particularmente emerge sua fé como dom total a Deus à serviço do seu reino no mundo;

3. é dom a ser acolhido na própria vida como o fez o discípulo amado.

Claro é que a Bíblia não fala da vida glorificada ou celeste de Maria, sobre a qual insiste a piedade popular, mas não falta no Magnificat a profecia sobre o louvor a ela por todas as gerações $($ Lc 1,48). Indício de uma veneração já presente nas comunidades do NT, que confirmar-se-á com a experiência cristã da ajuda de Maria nos momentos difícieis, como documenta o Sub tuum praesidium.

Trata-se de uma insistência sobre a «figura de Maria, tal como foi delineada no evangelho», que «é a medida mais alta com a qual medir toda e qualquer outra imagem mariana», e seu exemplo ético e espiritual. De fato, «como se sabe, o forte da piedade popular mariana é o nexo afetivo, enquanto que o elemento mais fraco é o nexo ético, a saber, a imitação».61 Seria reforçado, assim, o equilíbrio entre a Maria viva e glorificada e a Maria histórica e bíblica, entre a sua vita celeste e a terrena. ${ }^{62}$

\subsection{Favorecer o encontro entre a piedade popular e a liturgia}

Enquanto normalmente na primeira fase pós-conciliar havia uma tendência a sublinhar o primado da liturgia e a sua autosuficiência, hoje reconhece-se a possibilidade e a utilidade de um recíproco influxo. A síntese oficial foi codicada pelo Diretório sobre piedade popular e liturgia, onde afirma-se que «liturgia e piedade populare são duas expressoes legítimas do culto cristão, ainda que não homologáveis. Não devem ser opostas, nem equiparadas, mas harmonizadas» (n. 58).

Certamente a liturgia tem muito a oferecer à piedade populare, alimentando-a com a Palavra de Deus e conduzindo-a ao mistério pascal e suas implicações vitais. As peregrinações, por exemplo, devem considerar a confissão ou reconciliação como etapa importante, enquanto encontro com Cristo que perdoa, e reconhecer à Missa e à comunhão eucarística a caraterística de cume ou meta. ${ }^{63}$

\footnotetext{
${ }^{61}$ Boff, Mariologia social, 586.

${ }^{62}$ Estas duas fases estão presentes na piedade popular calabrês, ainda que tenha maior destaque a primeira. Cf. Tortora, Per una devozione popolare autentica verso la Madre di Dio, e Pretto, Santi e santità nella pietà popolare Calabria, I, 23; Id., La pietà popolare in Calabria, 351-402.

${ }^{63}$ Cf.S. De Fiores, «La Madonna anima della pietà popolare per un autentico incontro con Cristo», in Maria presenza viva nel popolo di Dio, Roma 1980, 178-183.
} 
Mas, também, a piedade popular, com suas formas de expressão ricas de valores criativos, intuitivos, cheios de significados e eloqüentes, pode trazer novo vigor à liturgia. A liturgia poderia, assim, recuperar o sentido da festa, da comunidade, da participação cordial.

A respeito da presença de Maria no mistério pascal, expressa pela piedade popular, significativa é a afirmação do Diretório que realiza uma interessante mudança. Ao contrário dos bispos que assumiram, após a segunda guerra mundial, uma posição negativa sobre as funções populares da sextafeira santa e da Páscoa, o Diretório interpreta-as positivamente como representações de asserções litúrgicas:

a piedade popular intuiu que a associação do Filho à Mãe é constante; na hora da dor e da morte, na hora da alegria e da ressurreição. A afirmação litúrgica, de que Deus encheu de alegria a Virgem na ressurreição do Filho, foi traduzida e quase representada pela piedade popular no pio exercício do Encontro da Mãe com o Filho ressuscitado: na manhã da páscoa, duas procissões, uma com a imagem da Mãe das dores, a outra com a do Cristo ressuscitado, encontram-se para significar que a Virgem foi a primeira a participar plenamente do mistério da ressurreição do Filho (n. 149).

De fato, não é difícil endossar o quanto afirma, após "observação participante", nosso estudioso Ignazio Schinella:
A piedade popular da semana santa concentra toda sua a- tenção no evangelho de João, tentando ser uma tradução popular desse e uma espécie de lectio muito simbólica e profunda, de tom espiritual marcante, com aprofunda- mento dos aspectos cristológicos e eclesiais contidos na presença de Maria nos pontos cruciais da morte e da re- surreição do Senhor. [...] A presença de Maria no Ociden- te durante o período pascal é uma ação conjunta do Espí- rito e da Igreja para suprir o silêncio que o evangelho tem sobre a presença de Maria. Do ponto de vista hermenêu- tico poder-se-ia dizer que a piedade popular ocupa e redi- ge nos espaços em branco do texto evangélico». ${ }^{64}$

\footnotetext{
${ }^{64}$ I. Schinella, «La Madre di Gesù associata al mistero della Croce e della risurrezione secondo la pietà popolare», in S. De Fiores - G. Strangio - E. Vidau (ed.), Popolo sacerdotale in cammino con Maria, Atti del XVIII Colloquio internazionale di mariologia, Gerace-San Luca (RC), 13-15 ottobre 2005, Roma 2008, 165-177.
} 
Da valorização à luz da Bíblia, pode-se passar a uma integração litúrgica de tais representações populares, que marcam os participantes por toda vida?

É o que propõe com oportunas motivações o próprio Ignazio Schinella, após ter dedicado atenção ao tema em alguns volumosos estudos. Ele não é a favor de uma «comemoração sóbria», a ser introduzida na liturgia da Sexta-feira santa, isto é, de «uma memória sóbria, densa, desarticulada da consideração do conteúdo cristológico e eclesiológico de Jo 19, 25-27», e, portanto, «não sugerida pelo sentimento ou por uma piedade deteriorada». ${ }^{65}$ $\mathrm{O}$ estudioso calabrês preconiza numa perspectiva mais ampla a entrada na liturgia de todas as expressões marianas populares, principalmente aquelas vinculadas à Semana santa, seja a Chiamata della Madonna na pregação da paixão, ${ }^{66}$ seja a Affruntata no dia da Páscoa: ${ }^{67}$

Por isto o meu sonho e, ao mesmo tempo, minha batalha, é que todas as manifestações da piedade popular, especialmente as da Semana santa, um dia façam parte da liturgia viva da Igreja. ${ }^{68}$

A proposta, com todas as decantações possíveis, é coerente com a interpretação cultural da piedade popular, ainda que precise estar atenta a não

\footnotetext{
${ }^{65}$ I.M. Calabuig, «La portata liturgica della esortazione apostolica "Marialis cultus"», in Notitiae 1874, 198-216, qui 207, nota 29). Na mesma linha de «discreta memoria della Vergine accanto alla croce nella liturgia del venerdì santo, sul modello della liturgia bizantina e delle liturgia orientali in genere» apresenta-se P. Sorci, «Maria presso la croce nella liturgia romana», in Theotokos 7 [1999] 417-448, qui 446.

${ }^{66}$ As tradições acerca da presença de Maria nos sermões da paixão são variadas. Em San Luca, por exemplo, a Chiamata della Madonna na tarde da Sexta-feira Santa é tríplice tendo como base a sua presença na paixão do Filho: na primeira vez é chamada enquanto comemora-se o encontro com Jesus no caminho do Calvário (IV estação da Via sacra), na segunda vez para ouvir Jesus crucificado que a proclama Mãe do discípulo amado, e na terceira vez para entregar-lhe o Filho morto. São cenas cheias de comoção e de rogos em alta voz dos presentes. Na igreja matriz de $S$. Maria della Pietà já há muitos anos alternamos Pe. Pino Strangio e eu na interpretação do relato da paixão, intercalado por cantos em dialeto calabrês e comentado por alguns sinais (saudação da cruz, aparição do anjo consolador no Getsemani, apresentação do Ecce homo). Tudo conclui-se com uma procissão noturna ao Calvário, enquanto o povo canta "Quandu la Matri santa caminava...»

${ }^{67}$ Quanto ao Affruntata é interessante a variante documentada pelo historiador Giovanni Fiore: «Si accresce la Festa nella città di Gerace con una Processione di mattina col concorso di quasi tutta la Città, e l'uno, e l'altro Clero Secolare, e Regolare; nella quale con mirabile artificio s'incontrano insieme la Vergine da lutto con Cristo Sacramentato, al cui incontro svestita la Madre dei suoi lutti, adora il suo carissimo Figliuolo. Incontro, qual riempie di molta tenerezza d'affetto i circostanti» (G. Fiore, Della Calabria illustrata, tomo II, Stamperia di Domenico Rosselli, Napoli 1743, 453).

${ }^{68}$ Schinella, Cattolicesimo e pietà popolare, 217.
} 
realizar uma inserção material e indiscriminada de todas as devoções do povo na liturgia.

\subsection{Unir a piedade mariana popular à vida: inculturação}

Chegamos ao ponto mais delicado e difícil: como realizar novamente uma inculturação da mensagem bíblica na vida do povo?

Não partiremos do nada, pois a piedade popular é considerada uma primeira forma de inculturação do cristianismo. Mas como tal operação foi automática e não consciente, é preciso uma nova evangelização mais consciente e capaz de evitar o excesso de que a cultura esteja acima e condicione a aceitação integral da revelação e o defeito, ou seja, uma inculturação na qual prospera o sincretismo e a magia.

Dever-se-ía visar três objetivos.

\subsubsection{Potencializar os valores populares relativos à Maria.}

Para que uma inculturação alcance seus objetivos é necessário que vá às raízes culturais, isto é, ao Weltanschauung ou à maneira orgânica de viver do povo. Ali encontraremos valores onde a inserção de Maria é natural e benéfica. Valores como o significado da família, da vida a ser protegida desde o primeiro ao último instante, a importância da mulher, sobretudo, enquanto mãe, a aceitação do sofrimento e do revés, a hospitalidade, o senso de honra, de justiça, de liberdade, de amizade... Em todas estas raízes pode ser inserida a fé cristã e a sua referência a Maria.

Também no âmbito da devoção mariana devem ser valorizadas as intuições do povo sobre Maria: sua humanidade, sua presença viva, sua beleza, suas intervenções no território. Maria aparece como adotada pelo povo calabrês, porque ele sentiu-se considerado e amado eficazmente por ela.

\subsubsection{Purificar a piedade mariana popular.}

É óbvio, porém, que nem tudo funciona na cultura popular. Basta ler a segunda carta mariana do bispo Tortora para perceber as cinco pragas da Igreja na Calábria, para as quais, Maria oferece decisiva terapia. ${ }^{69}$ Hoje, em geral, a Calábria luta contra as formas de coexistência entre a devoção à

\footnotetext{
${ }^{69}$ F. Tortora, bispo de Gerace-Locri, «Messaggio di riconciliazione nel nome della Madre di Dio», in La Madonna di Polsi, speciale n. 3, pp. 3-5, onde são denunciadas as «cinco pragas da comunidade calabrês»: separação entre fé e vida, cultura da morte, desvalorização da liberdade, idolatria do ter, conflito de classes.
} 
Nossa Senhora e a criminalidade. Já o ensinamento de são Luís Maria de Montfort (1673-1716) dirigia-se contra aqueles que abusavam da devoção mariana para continuar empedernidos na vida pecaminosa:

Os devotos presuntuosos são pecadores escravos de suas
paixões e amantes do mundo. [...] Dormem tranquilla-
mente em seus maus hábitos, sem esforçar-se por corre-
ção, sob o pretexto de serem devotos de Maria. [...] Na-
da no cristianismo, é mais condenável do que esta dia-
bólica presunção. [...] Afirmo que símile abuso da devo-
ção à Virgem santa [...] costitui horrível sacrilégio...

É o caso de chamar em causa o ensinamento profético e evangélico sobre a natureza do verdadeiro culto, unido ao testemunho de vida, ao exercício da caridade e da justiça. Tal catequese libertaria a piedade mariana popular da tendência mágica, do passivo abandono a forças cegas, enquanto promoveria a mística do povo que coexiste com o empenho cristão e com a criatividade nas expressões devotas.

\subsubsection{Promover novas expressões de piedade mariana.}

Recordando a esplêndida indicação da Marialis cultus (1974) que quer promover não somente a renovação da piedade mariana, mas, também, o «impulso criativo» de novas expressões (MC), é preciso convencer-se da necessidade de novas expressões, fruto natural de uma piedade renovada a partir dos critérios e das orientações da própria Marialis cultus, isto é, a referência trinitária, cristológica, eclesiológica, a inspiração bíblica, litúrgica, ecumênica e antropológica. Atentos, também, à via pulchritudinis e à narratologia, devem surgir novos títulos e invocações, novos cantos, novos contos e nova iconografia. ${ }^{71}$ É um campo aberto onde a fé madura e a fantasia popular saberão encontrar sinais e propostas devotas ainda não imagináveis.

\section{Aspectos conclusivos}

\subsection{Do desinteresse à acolhida}

Com a satisfação do povo de Deus a avaliação da piedade popular passou da indiferença e do desprezo ao reconhecimento do seu valor humano

\footnotetext{
${ }^{70}$ San Luigi Maria di Montfort, Trattato della vera devozione a Maria, nn. 97-99.

${ }^{71}$ Cf. Boff, Mariologia social, 573.
} 
e cristão. Realizou-se uma transição «da traição-exílio à acolhida persistente, à inserção». ${ }^{72}$

Houve um processo de compreensão de que a piedade popular não faz parte somente de uma cultura em sentido antropológico, que não é lícito suprimir ou desprezá-la, mas é uma forma de inculturação do cristianismo, com a mesma dignidade de outros processos de inculturação da fé. $\mathrm{O}$ fenômeno está ligado à religião, mas também à fé, enquanto provêm do Espírito e produz bons frutos. Nessa perspectiva escreveu-se:

Quando falamos de piedade popular, a qualificação de popular deve ser entendida em seu significado não sociológico, mas teológico e eclesiológico, ou seja, do povo de Deus enquanto comunidade do ágape daqueles que crêem em Jesus Cristo ${ }^{73}$.

Quanto à sua vitalidade, ainda que enfraquecida a forma cultural in auge do mundo pastoril ou rural do século XVIII - como observou acuradamente Corrado Alvaro ${ }^{74}$ - a piedade popular continua a viver de maneira transversal no povo de Deus. Este é o motivo da persistência ou incremento dos santuários de peregrinações ou dos cantos e das tradições populares.

\subsection{Maria referência viva e pessoal}

Na cultura popular, salvaguardada a centralidade de Cristo, emerge a figura de Maria como pessoa viva e presente, com toda carga de bondade, de santidade e de poder, que manifesta na história individual e social do povo. É um valor importante num tempo de atrofia do sentimento religioso e de eclipse de Deus, que não é possível ocultar, mas sim, valorizar.

Das preciosas orientações do magistério da Igreja, dentre as quais a do Diretório sobre piedade popular e liturgia (2002), conclui-se que é preciso elaborar uma mariologia popular orgânica ou sistemática, na qual converjam as istâncias mais válidas da cultura popular e da fé eclesial. O itinerário que parte da experiência do povo de uma Maria glorificada e auxiliadora deve ser completado pela Palavra de Deus e pela tradição, para depois confrontarse com a liturgia e com a vida.

\footnotetext{
${ }^{72}$ Schinella, Cattolicesimo e pietà popolare, 3 .

${ }_{74}^{73}$ Schinella, Cattolicesimo e pietà popolare, 217.

74 «Come al contatto dell'aria le antiche mummie si polverizzano, si polverizzò questa vita. È una civiltà che scompare, e su di essa non c'è da piangere, ma bisogna trarre, chi ci è nato, il maggior numero di memorie» (C. Alvaro, Gente in Aspromonte, Milano 1970, 15).
} 
A hosmose e a pacífica, ainda que dialética, relação da piedade popular mariana com a fé e a liturgia da Igreja, acabará por beneficiar ambas, conferindo à liturgia uma característica mais festiva, emocional e comunitária, e à piedade popular mariana um tom mais expressamente cristocêntrico, trinitário e eclesial.

Renovada e revitalizada a piedade popular terá um novo esplendor, assumindo o lugar entre as atuações do Espírito na história e na geografia da graça.

\section{Resumo}

O autor preocupa-se em estabelecer a relação entre a figura bíblica de Maria e sua inculturação popular. Inicialmente esclarece dois problemas: qual é a situação atual da piedade popular e qual atitude devemos assumir em relação a ela. Depois disso detem-se na percepção de Maria por parte do povo, após situá-la no universo da cultura popular. Concluindo intenta propor uma mariologia populare, muovendo-se a partir de princípios e critérios.

Palavras-chave: Maria, Inculturação Piedade popular, Mariologia.

\section{Riassunto}

L'autore si preoccupa di stabilire il rapporto tra la figura biblica di Maria e sua inculturazione popolare. Inizialmente cerca di chiarire due problemi: qual è la situazione attuale della pietà popolare e quale atteggiamento dobbiamo assumere nei suoi confronti. Per poi soffermarsi sulla percezione di Maria da parte del popolo, dopo averla situata nell'universo della cultura popolare. Infine intenta proporre una mariologia popolare, muovendo da alcuni principi e criteri.

Parole-chiavi: Maria, Inculturazione, Pietà popolare, Mariologia.

Stefano De Fiores

Superior e Diretor do Centro Mariano Monfortano Professor Ordinário Emérito da Pontifícia Universidade Gregoriana Doutor em Teologia Espiritual pela Pontifícia Universidade Gregoriana de Roma Professor de várias disciplinas mariológicas na Pontifícia Faculdade Teológica

Marianum

Artigo Recebido em 27/09/2010 Artigo Aprovado em 21/12/2010 